\title{
MEMAKNAI EMOSI SEBUAH KOTA MELALUI FOTOGRAFI JALANAN
}

\author{
Mastita Bibsy Zainnahar ${ }^{1)}$, Wisnu Dwicahyo ${ }^{2)}$ \\ Program Studi Desain Komunikasi Visual, \\ Fakultas Bahasa dan Seni, Universitas Indraprasta PGRI \\ Jl. Nangka 58 C Tanjung Barat, Jakarta Selatan, 12530, Indonesia \\ mastitabibsy@gmail.com
}

\begin{abstract}
Abstrak
Fotografi jalanan adalah salah satu genre yang banyak diminati karena keunikan yang dimilikinya, fokus utama fotografi jalanan adalah pergerakan manusia di dalam ruang publik yang memberikan sebuah cerita. Segmentasi fotografi jalanan adalah wilayah perkotaan karena memiliki dinamika dan ketegangan dibanding dengan pedesaan. Dalam teknik pengambilan fotografi jalanan insting seorang fotografer diperlukan agar tepat mengambil momen dan mampu mengendalikan cahaya agar foto yang dihasilkan tetap memiliki estetika. Penelitian ini menggunakan metode kualitatif deskriptif, data yang dikumpulkan berasal dari buku dan jurnal ilmiah mengenai fotografi jalanan yang mendalam. Tujuan dari penelitian ini adalah untuk mengetahui bagaimana memaknai emosi sebuah kota melalui fotografi jalanan. Hasil dari penelitian ini menunjukan bahwa dalam memaknai emosi sebuah kota lewat fotografi jalanan harus tahu dulu di mana fotografi jalanan itu bergerak dan apa yang ingin disampaikan tidak hanya sebuah estetika, tetapi ada cerita dan pesan di dalamnya. Fotografi jalanan bukan hanya tentang keramaian yang dilukis lewat cahaya, tetapi juga tentang gambaran sebuah emosi yang kuat.
\end{abstract}

Kata Kunci: Fotografi Jalanan, Kota, Manusia

\begin{abstract}
Street photography is a genre that is in great demand because of its uniqueness, the main focus of street photography is the movement of people in public spaces that tell a story. The segmentation of street photography is in urban areas because it has a dynamic and tension compared to rural areas. In the technique of taking street photography, a photographer's instinct is needed to precisely take the moment and be able to control the light so that the resulting photo still has an aesthetic. This research uses descriptive qualitative method, the data collected comes from books and scientific journals on in-depth street photography. The purpose of this research is to find out how to interpret the emotions of a city through street photography. The results of this study indicate that in interpreting the emotions of a city through street photography, we must first know where street photography moves and what it wants to convey is not only an aesthetic, but also a story and a message in it. Street photography is not just about a crowd painted through light, but also about depicting a strong emotion.
\end{abstract}

Keywords: Street Photography, City, Human

Correspondence author: Mastita Bibsy Zainnahar, mastitabibsy@gmail.com, Jakarta, and Indonesia 


\section{PENDAHULUAN}

Fotografi adalah teknologi sekaligus seni yang dijumpai dalam berbagai bidang kehidupan manusia. Fotografi diaplikasikan untuk keperluan dokumentasi, misalnya dalam keluarga, jurnalistik, maupun pengarsipan dalam lembaga. Fotografi juga digunakan untuk keperluan relasi sosial, misalnya snapshot, fotografi selebriti, dan persuasi komersial, seperti halnya fotografi fashion. Disamping itu, fotografi juga dipakai untuk keperluan eksplorasi kreatif maupun reflektif, seperti halnya dalam fotografi seni. Perkembangan pemahaman teoritis tentang fotografi seiring dengan perkembangan teknologi fotografi sejak era pra-fotografi, fotografi analog, hingga fotografi digital menyebabkan paradigma pemikiran kritis tentang fotografi bergeser kearah kultural, dengan fokus penalahaan pada makna fotografi bagi pengalaman hidup manusia. Pada titik ini estetika fotografi mengalami sebuah tantangan ke tingkat yang tidak pernah dipikirkan sebelumnya. Estetika fotografi dihadapkan pada sebuah situasi yang problematis dan kompleks ketika berhadapan dengan status seni fotografi. Fotografi telah membuktikannya dengan menghadirkan dirinya sebagaimana layaknya media seni rupa yang lain bahwa karya-karyanya dapat menjadi medium ekspresi si pemotretnya (fotografi ekspresi) baik itu secara konseptual maupun dalam bentuk 'gaya' atau dengan cara tertentu dalam menampilkan karyanya (Soedjono, 2006:4). Banyak sekali genre di dalam fotografi salah satunya adalah street photography dimana genre ini memiliki segmentasinya sendiri para penyuka street fotografi ini biasanya adalah orang-orang yang tertarik dengan kehidupan diperkotaan.

Street Photography atau lebih dikenal dengan fotografi jalanan merupakan salah satu cabang fotografi yang membidik kehidupan masyarakat urban yang berada di jalan dan sekitarnya dengan memotret apa adanya tanpa mengarahkan dan lebih mengutamakan subjek atau point of interest di ruang publik. Jenis fotografi ini bersifat dokumenter, foto seri atau foto tunggal. Penamaan "fotografi jalanan" ini merupakan istilah yang mengacu pada objek fotografi yang ada. Terutama menyangkut lokasi dan situasi suatu objek di "jalanan” tertentu. Namun karena dari sisi sejarahnya bahwa fotografi ditemukan dan berkembang pada abad XIX dengan mengabadikan berbagai objek yang ada di dalam kota, maka konteks "jalanan" di dalam kota. Kota yang dimaksud adalah "wadah", yang berisikan berbagai aspek kehidupan manusia urban dengan segala interaksinya dengan lingkungannya (Soedjono, 2006: 146).

Perkembangan fotografi jalanan saat ini tidak lepas dari sejarah fotografi yang lahir pada akhir abad ke-18 dan awal abad ke-19, pada masa pertumbuhan kota industri, yang dibangkitkan oleh kehebatan kesusastraan dan seni dalam merespon meningkatnya pengaruh daerah perkotaan khususnya London, Paris, dan New York. Pada abad ke-19 tersebut, kota menjadi sentral gambar untuk kamera dalam berbagai bentuk pendekatannya. Di Indonesia, aliran fotografi ini masih tergolong baru dibandingkan dengan aliran lainnya. Fotografi jalanan baru mulai berkembang di Indonesia pada sekitar tahun 1990, dan semakin populer pada awal dekade tahun 2000 seiring berkembangnya teknologi fotografi digital.

Potongan kecil abstraksi ruang publik pada suatu kota memberikan gambaran kepada manusia bahwa ruang publik sebagai ruangnya. Berdasar atas sisi keruangan, "jalanan" merupakan ruang publik yang memungkinkan terjadinya berbagai interaksi sosial dari berbagai tataran sosial masyarakat (Soedjono, 2015). Ruang publik ini dapat disikapi dengan berbagai aspek yang melingkupinya, antara besar dan kecil, antara siang dan malam, antara luas dan sempit, tinggi dan rendah serta berbagai kontras fisik maupun psikis antara benda hidup dan mati. Objek merupakan kehidupan yang kompleks, dapat berupa manusia, jajaran gedung-gedung dengan segala keunikan arsitekturnya, poster yang terkoyak, rambu-rambu lalulintas, kendaraan yang lalu lalang, maupun parkir di pinggir jalan, tempat sampah, corak-corak grafiti pada dinding. Objek-objek tersebut mungkin memiliki keunikan yang tersembunyi dan kehadirannya yang sering tidak dapat perhatian cukup. Objek-objek tersebut apabila dicermati, diteliti, dan dapat diabadikan, ternyata akan memiliki nilai humanitas yang tidak terduga.

Apa yang ingin disampaikan lewat fotografi jalanan berbeda dengan genre yang lain karena objek yang diangkat juga berbeda, fotografi jalanan adalah gambaran jelas dari apa yang sering terjadi di ruang publik atau perkotaan dimana banyak hal terjadi dan bisa menjadi sebuah 
cerita yang menarik. Teknik yang digunakan dalam fotografi jalanan juga terbilang susah-susah gampang karena sebenarnya insting fotografer lebih berperan dalam menjepret setiap momen yang ada. Ruang gerak fotografi jalanan didalam kota membuat kita sadar bahwa kota bukan hanya sekedar tempat tinggal tapi memiliki hal lain yang coba digambarkan lewat fotografi jalanan tanpa melupakan estetika karena fotografi tetap bagian dari seni visual.

\section{METODE PENELITIAN}

Metode penelitian yang digunakan adalah metode peneltian kualitatif. Metode penelitian kualitatif adalah penelitian yang menggunakan metode observasi, analisis isi, dan metode pengumpulan data lainnya yang menyajikan respon-respon dan perilaku subjek (Setyosari, 2012: 24). Tahap observasi deskriptif adalah penelitian yang belum membawa masalah tentang apa yang akan diteliti sehingga peneliti melakukan penjelajahan umum dan menyeluruh, melakukan deskripsi terhadap semua yang dilihat, didengar, dan dirasakan (Agustinova, 2015: 44).

Teknik pengumpulan data dalam penelitian ini menggunakan data sekunder yang bersumber dari studi literasi yang bertujuan agar analisis yang dilakukan akurat dan tersampaikan dengan baik, serta bersumber dari jurnal atau artikel yang sama sebagai pembanding dari artikel ini. Objek dalam penelitian ini berfokus kepada memaknai emosi dari sebuah kota melalui fotografi jalanan berdasarkan simbol-simbol yang berupa aktivitas masyarakat, bangunanbangunan, dan tata ruang kota.

\section{HASIL DAN PEMBAHASAN}

Fotografi jalan adalah ekspresi dari sebuah kota yang diambil untuk memberikan sebuah pesan, sering sekali hasil jepretan fotografer jalanan menunjukan hal yang realistis karena memang pengambilan foto secara candid atau apa adanya. Di dalam fotografi jalanan banyak hal yang bisa diangkat seperti aktivitas masyarakat, bangunan dan kesibukan yang ada di perkotaan yang memiliki nilai sendiri bagi para penggemar fotografi jalanan. Segmentasi fotografi jalanan sendiri adalah kota-kota besar dimana ruang publiknya lebih ramai berbeda dengan pedesaan yang lebih menggambarkan damai, sepi dan tenang. Bisa dibilang fotografi jalanan dapat dinikmati oleh siapapun khususnya mereka yang memiliki hubungan dengan kota-kota besar seperti Jakarta. Di dalam fotografi jalanan cerita lebih di kedepankan di banding nilai estetika, karena biasanya fotografer jalanan ingin memberikan pesan sesuai keadaan yang ada tanpa banyak mengeditnya.

Menurut Erik Prasetya (2014), meskipun memiliki irisan, fotografi jalanan dapat dibedakan dari fotografi dokumenter atau fotografi jurnalistik. Sebagai titik pangkal. jalanan adalah sebuah pendekatan yang berusaha menangkap emosi sebuah kota dengan berbagai cara. cara-cara dalam pendekatan tersebut khas dan bisa dibedakan dari jenis pendeketan lain. Berbeda dengan fotografi dokumenter, fotografi jalanan bersifat subjektif, diambil secara candid atau alami serta mengutamakan estetika daripada kelengkapan informasi. Namun sebaliknya, fotografi dokumenter bersifat objektif, bisa direka, serta lebih mengutamakan kelengkapan informasi daripada estetika. Pada intinya fotografi jurnalistik memotret di ruang publik, bukan ruang privat. Ruang publik bisa bersifat konkret, seperti jalanan, taman, pasar, atau kendaraan umum. Bisa juga bersifat konseptual, yakni relasi manusia dengan ruang publik, bukan dunia batin. Pendekatan fotografi jalanan sendiri semakin populer dengan adanya perkembangan teknologi kamera serta media informasi internet dan media sosial.

Fotografer jalanan harus memahami bagaimana dinamika sebuah kota karena mereka harus mampu mengambil momen yang bagus ditengah hiruk-pikuk kota besar seperti Jakarta. Lebih dari separuh penduduk dunia tinggal diperkotaan. Fotografer jalanan tidak tertarik pada keindahan alam, matahari tenggelam, bulan purnama, jika itu tidak dimaknai dalam hubungannya di ruang publik (Prasetya, 2014:13). Manusia menjadi subjek utama dari fotografi jalanan karena setiap gerak manusia memiliki cerita apalagi dalam ruang publik, pergerakan manusia yang tidak seirama pun menjadi daya Tarik dan banyak harmonisasi antara elemen kota dengan manusia. Fotografi jalanan selalu bercerita akan sesuatu dan biasanya memiliki makna yang dalam. Untuk hasil foto yang bagus dan meliki nilai estetika di dalamnya biasanya dilakukan oleh fotografer professional, tetapi seiring perkembangan jalan dan dengan adanya teknologi siapa pun bisa 
memotret di jalanan dan tidak ada batasan dalam berkarya walaupun tetap teknik mendasar itu diperlukan.

\section{Teknik Dalam Fotografi Jalanan}

Dalam memotret tidak hanya alat yang harus dimiliki tetapi setidaknya teknik mendasar juga harus dipunyai seseorang dalam memotret, tanpa disadari sebagai masyarakat awam kita sudah melakukan teknik-teknik mendasar tersebut dalam mengambil sebuah foto lewat kamera handphone yang kita miliki. Ada tiga hal penting yang harus ada dalam memotret yaitu media rekam (kamera), media penyimpanan, dan cahaya. Aspek terpenting dalam fotografi adalah cahaya bila tidak ada cahaya, fotografi tidak akan terbentuk (Gunawan, 2013:520). Untuk fotografer jalanan insting lebih berperan dalam teknik pengambilan foto karena fotografer harus memahami situasi dan kondisi dan juga tetap memperhatikan cahaya karena fotografer jalanan tidak bisa mengatur banyak sedikitnya cahaya seperti di studio foto, tetapi fotografer jalanan bisa mengatasi cahaya dengan teknik dan insting yang mereka miliki secara spontan karena mereka berpacu pada gerak dan waktu yang ada. Waktu yang baik dalam mengambil foto biasanya saat pagi hari dan sore hari karena cahaya matahari sedang bagus dan tidak terlalu terang kita menyebutnya dengan golden hour.

Dalam potret fotografi jalanan yang diutamakan adalah orang itu; siapa dia, apa karakternya, bagaimana benda-benda disekelilingnya menjadi atribut penontonnya (Prasetya, 2014:13) maka dari itu fokus utama seorang fotografer jalanan memanglah subjek dan objek mereka. Untuk fotografer jalanan profesional pengaturan kamera secara mendasar sudah harus dimiliki agar dapat membantu dalam pengambilan foto jika seorang fotografer jalanan tidak cekatan dalam mengatur kamera mereka maka dapat kehilangan momen yang baik. Fotografi jalanan memiliki karakter yaitu foto candid, kelengkapan informasi tidak diutamakan, berisi peristiwa sehari-hari, dan elemen yang ada dapat membangun suatu komposisi visual.

Penampilan untuk seorang fotografer jalanan juga sangatlah penting mereka tidak boleh berpenampilan yang mencolok, biasanya seorang fotografer jalanan menggunakan pakaian yang sangat sederhana dan nyaman untuk dipakai di luar ruang. Penampilan yang mencolok akan menimbulkan situasi yang tidak baik maka dari itu pemilihan ukuran kamera juga berpengaruh sebaiknya seorang fotografer jalanan menggunakan kamera yang kecil dan lensa yang tidak terlalu besar untuk menghindari hal-hal yang tidak diinginkan karena mereka bergerak di dalam ruang publik. Fotografi jalanan membebaskan juru foto dari kepentingan langsung perdokumentasian, kebaruan dan kelengkapan informasi (meski tidak menolaknya). Fotografer jalanan pun memiliki kemewahan terbatas dari kerangka kerja fungsional. Kemewahan inilah yang seharusnya dimanfaatkan fotografer jalanan dengan etika yang dicoba dijaga (Prasetya, 2014: 26).

\section{Manusia sebagai Subjek}

Manusia adalah makhluk yang istimewa setiap geraknya meninggalkan sebuah cerita dan ini yang coba diangkat para fotografer jalanan, sering kita melihat hasil dari foto jalanan adalah kesibukan manusia dalam menjalani keseharian mereka. Fotografi jalanan memberi kemungkinan lebih besar bagi kita mendekati manusia dalam segala karakter dugaannya (Prasetya, 2014:26). Karakter yang terekam lewat lensa fotografi jalanan memiliki nilai estetika karena dipadu padankan dengan elemen lain sebagai atribut pendukung seperti foto di atas yang diambil oleh Erik Prasetya pada bulan september 2014 di Jalan Sudirman depan Halte Polda di sini jelas sekali bahwa manusia adalah subjek dari foto tersebut. Jika kita menganggap orang sebagai subjek, maka dia punya otoritas terhadap dirinya sendiri. Dia punya kemauan, tujuan dan gerakan sendiri. Dia tidak bisa dipaksa tunduk ke dalam kerangka pikir dan kepentingan. Ketika fotografer mengatur orang lain untuk berpose atau melakukan informasi tertentu, membuat orang lain lebih mirip objek. Bukan berarti ini pasti buruk, tetapi pendekatan ini tidak memadai jika memang ingin berjumpa manusia. Jika mau melihat manusia, memang harus mencoba sebisa mungkin membiarkan orang-orang menjadi diri sendiri (Prasetya, 2014:28). 


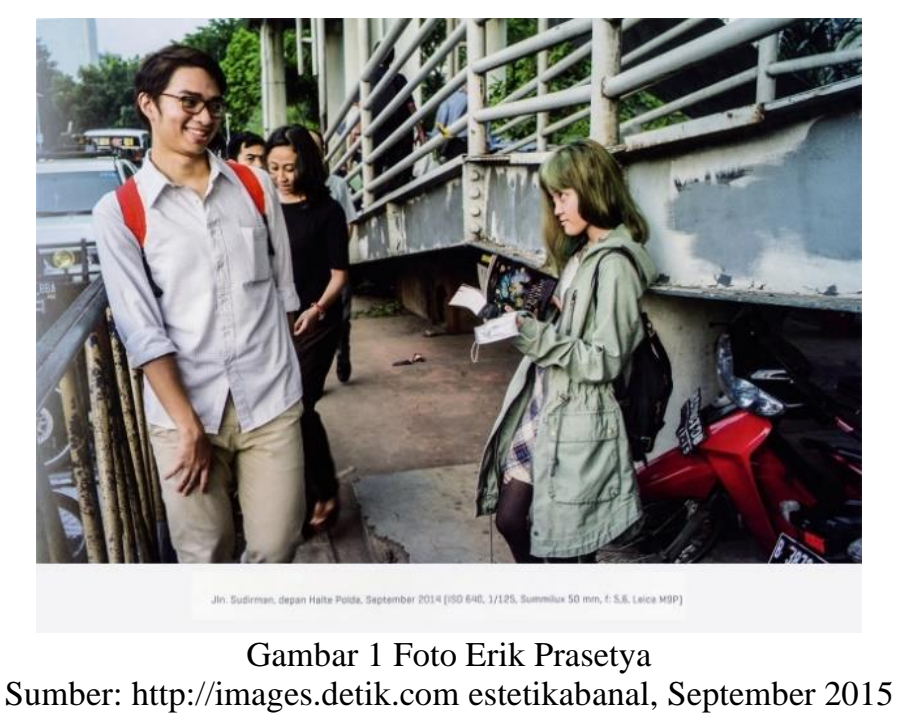

Dalam memaknai foto ini tentunya setiap individu memiliki pemaknaan yang berbeda apa pun itu tetap manusia adalah tokoh utamanya dan dapat dilihat bagaimana Erik Prasetnya mampu mengambil momen sehingga foto itu bercerita. Walaupun manusia adalah subjek utama, tidak boleh melupakan objek pendukung lainnya seperti infrastruktur dan yang lainnya karena tanpa objek pendukung ini esensi dari fotografi jalanan pastinya berkurang. Manusia dalam fotografi jalanan memang penting, tetapi jangan lupakan hal yang mampu menambah estetika dalam fotografi jalanan.

\section{Emosi Sebuah Kota}

Kota adalah sebuah pemukiman yang penduduknya relatif besar, padat, permanen, dan dihuni oleh orang yang heterogen. Pengertian ini menunjukkan bahwa kota memiliki jumlah penduduk yang sangat besar dan padat (Asy'ari, 1993: 19). Kota merupakan ruang untuk fotografi jalanan, dimana kota tempat para fotografer jalanan memburu momen berharga. Dinamika sebuah kota memberikan satu gambaran bahwa kota juga memiliki emosi dan emosi tercipta oleh gerak manusia yang didukung suasana yang khas. Fotografi jalanan ingin menampilkan bahwa kota memiliki emosi, setiap kota memiliki emosi yang berbeda bahkan setiap sudut kota memiliki rasa atau emosi yang berbeda. Jakarta berbeda dengan Surabaya walaupun mereka sama-sama sebuah kota, yang membuat mereka berbeda adalah karakter masing-masing kota tersebut. Jakarta dikenal sebagai Ibu Kota dan Surabaya dikenal sebagai Kota Pahlawan mereka memiliki perbedaan artinya, emosi yang dimiliki juga berbeda.

Sebuah kota memiliki dinamika yang dapat diabadikan lewat sebuah foto, fotografer jalanan lebih berminat pada kota karena jejak peradaban dan ketegangan di kota lebih nyata dari pedesaan (Prasetya, 2014:13). Walaupun manusia adalah tokoh utama dalam fotografi jalanan bukan berarti fotografi jalanan memotret foto individu karena fotografi jalanan menggambarkan hubungan antar orang atau hubungan orang dengan sekelilingnya. Ingatlah, kota tidak terdiri dari satu orang, ruang publik bukanlah ruang privat, minat fotografi jalanan adalah pada emosi kota dan ruang publik (Prasetya, 2014:13). 


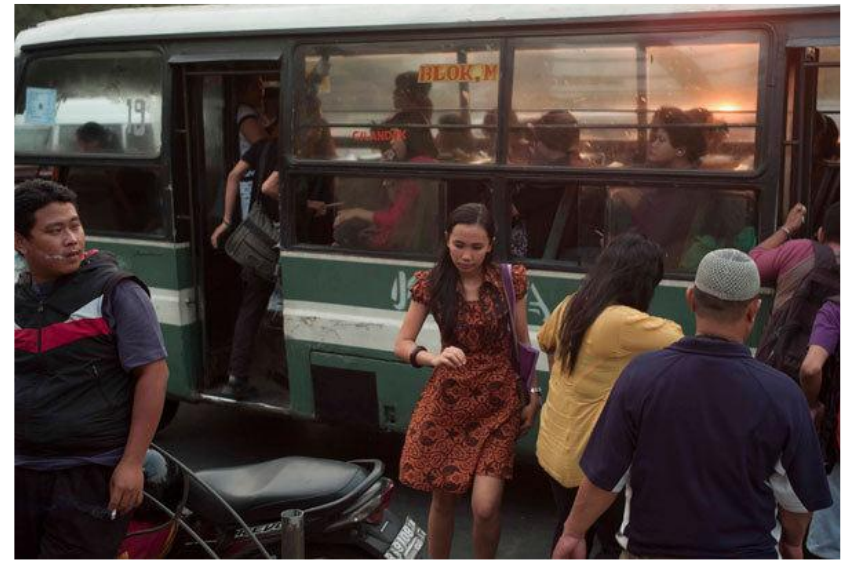

Gambar 2 Estetikabanal, karya: Erik Prasetya

Sumber: http://images.detik.com estetikabanal, September 2015

Dalam karya ini terlihat beberapa lapis aktivitas dalam satu bingkai gambar yang kita bayangkan. Lapis depan, tengah, dan belakang. Lapisan itu menciptakan komposisi atau pola yang bisa dipahami. Erik Prasetya berusaha menampilkan estetika lebih luas daripada sekedar keindahan atau kecantikan dengan menampilkan komposisi lapisan pola yang bisa difahami dengan menampilkan seorang pria pada lapisan depan sedang menghisap rokok, lapisan tengah wanita mengenakan baju bermotif batik berjalan melawan arah pada lapisan belakang yang antri untuk menaiki bus kota. Foto tersebut menyajikan kompisisi serta visualisasi yang padat dengan banyaknya objek lain sehingga menimbulkan kesan kesibukan dengan berbagai aktivitas yang terjadi pada kota tersebut.

Pemotretan karya tersebut menggunakan pengaturan kamera dengan iso 320, shutter speed $1 / 250$ dan $\mathrm{f} 5.6$. Penggunaan pengaturan tersebut menghasilkan foto ruang tajam objek pada keseluruhan menjadi tampak jelas. Kemudian menggunakan sudut pandang mata normal (eye level viewing) dengan format foto vertical, foto yang dihasilkan foto warna.

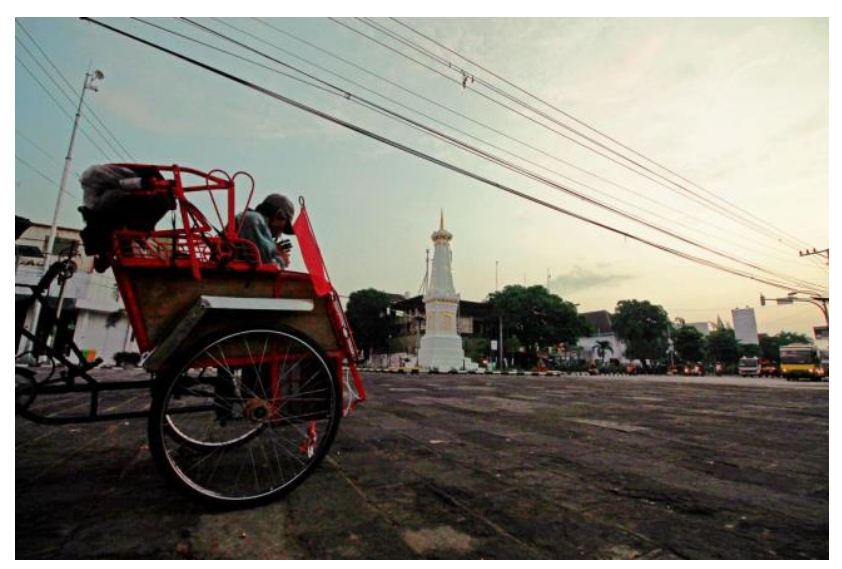

Gambar 3 Menikmati pagi, karya Ricky Priyantoso

Sumber: Karya Tugas Akhir “Stree Photography Kota Yogyakarta”, 2016

Dalam karya ini fotografer mengambil foto di depan Tugu Yogyakarta pada pukul 5.42 WIB pagi hari. Tugu adalah salah satu monumen kebanggaan Yogyakarta karena sejarahnya, sebab tugu itu juga sebagai daya tarik wisatawan yang datang ke Yogya. Mengabadikan tugu saat sepi dengan adanya tukang becak yang sudah siap menunggu penumpangnya di pagi hari. Warna langit yang masih kebiruan memperilhatkan eksotisnya suasana Yogyakarta pada pagi hari bersama trasportasi khas Yogyakarta. Foto yang diambil menggambarkan sebuah emosi yang ada 
pada Yogyakarta pada pagi hari, berbeda dengan contoh gambar sebelumnya yang meberikan kesan ramai dan penuh kesibukan, Yogyakarta lebih memberikan kesan sepi serta tenang pada setiap harinya.

Sekarang dengan berkembangnya teknologi siapa pun bisa memotret di jalanan dengan begitu semakin banyak orang yang melakukan kegiatan fotografi jalanan, tetapi tidak bisa menyamai hasil seorang fotografer profesional dengan amatiran karena insting yang digunakan berbeda, bagi fotografer jalanan, manusia dan kota adalah suatu kesatuan yang tidak dapat dipisahkan. Dalam memaknai emosi sebuah kota lewat fotografi jalanan harus tahu dulu di mana fotografi jalanan itu bergerak dan apa yang ingin disampaikan tidak hanya sebuah estetika, tetapi ada cerita dan pesan di dalamnya. Elemen-elemen dalam fotografi jalanan saling mendukung dan memberikan sebuah kesan bagi penikmatnya fotografi jalanan bukan hanya tentang keramaian yang dibungkus lewat estetika, tetapi juga tentang gambaran sebuah emosi yang kuat.

\section{SIMPULAN}

Fotografi adalah seni melukis menggunakan cahaya yang dapat dijumpai di berbagai bidang kehidupan, dan di dalam fotografi terdapat berbagai genre salah satunya adalah fotografi jalanan. Fokus dari fotografi jalanan adalah pergerakan manusia didalam ruang publik di mana ini coba diangkat dalam sebuah karya foto. Manusia adalah makhluk yang istimewa di mana setiap pergerakannya memberikan sebuah cerita ditambah dengan suasana perkotaan yang memiliki ketegangan dan manusia adalah subyek utama dari fotografi jalanan. Perkotaan yang memiliki dinamika menjadi pembeda dari pedesaan maka dari itu ruang lingkup fotografi jalanan adalah perkotaan. Sebuah kota memiliki emosi karena di dalamnya ada sebuah kehidupan yang bermacam-macam, penduduk di kota lebih banyak di banding di pedesaan dan aktivitasnya lebih sering bahkan sebuah kota bisa dibilang tidak pernah tidur. Memaknai emosi sebuah kota lewat fotografi jalanan adalah hal tepat karena ruang lingkup fotografi jalanan adalah kota, emosi ini dibungkus dalam satu momen yang tidak bisa terulang dan fotografi jalanan bukan hanya memotret di jalan, tetapi mengabadikan momen yang memiliki cerita dan tersusun atas elemenelemen visual yang menciptakan nilai yang bukan hanya tentang estetika.

\section{DAFTAR PUSTAKA}

Agustinova, D. E. (2015). Memahami metode penelitian kualitatif teori \& praktik. Yogyakarta: Calpulis.

Asy’ari, S. I. (1993). Sosiologi kota dan desa. Surabaya: Usana Nasional.

Gunawan, A. P. (2013). Pengenalan teknik dasar fotografi. Humaniora, 4(1), 518-527.

Kusrini. (2016). Fotografi jalanan: Membingkai kota dalam cerita. Journal of Urban Society's Arts, 3(2). 102-109.

Prasetya, E. (2014). On street photography. Jakarta: Gramedia.

Priyantoso, R. (2016). Street photography Kota Yogyakarta. Universitas Negeri Yogyakarta.

Republika.co.id. (2014, 16 Juni). Semarak fotografi jalanan. Diakses pada 02 Juli 2020, dari https://republika.co.id/berita/koran/urbana/14/06/16/n7991s40-semarak-fotografijalanan

Setyosari, P. (2012). Metode penelitian pendidikan dan pengembangan. Jakarta: Kencana.

Soedjono, S. (2007). Pot-Pourri fotografi. Jakarta: Penerbit Universitas Trisakti. 